\title{
ESTADO, PROPRIEDADE E TRABALHO \\ EM I. KANT
}

\author{
José N. Heck \\ UFG-CNPq/ UCG
}

Resumo: As teorias da apropriação originária seguem, em Locke como em Kant, o mesmo esquema racional, ou seja, quando um homem assume determinada conduta em relação a certo objeto ele torna-se o dono do mesmo e adquire em relação aos demais seres humanos o direito de excluí-los do uso do objeto. Mas, enquanto na teoria lockiana a causa fundante e a sustentação de validade da propriedade convergem, Kant distingue claramente a base empírica do plano normativo. Para o doutrinador alemão, uma coisa é submeter a natureza aos propósitos do homem e outro, bem diferente, é sustentar a utilização exclusiva de algo e vedar, assim, aos demais o uso legítimo do objeto. A trabalho pretende contribuir para o esclarecimento das relações entre trabalho, propriedade, Estado e a manutenção da paz social.

Palavras-chave: Kant, trabalho, propriedade, Estado, Locke, direito e paz.

Abstract: In both Locke and Kant, original appropriation theories follow the same rational pattern, that is, when a man assumes a specific conduct with respect to a certain object, he becomes its owner and acquires the right to exclude the rest of human beings from its use. But, whereas in the Lockean theory the founding cause and what sustains the validity of property converge, Kant distinguishes clearly the empirical basis from the normative level. For the German doctrinaire, it is one thing to subdue nature to man's own ends, but quite another to sustain the exclusive use of an object 
precluding the rest from its legitimate use. This paper intends to contribute to the clarification of the relationship between labor, property, State and social peace-keeping.

Key words: Kant, labor, property, State, Locke, social peace.

\section{Introdução}

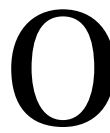

primado autônomo da razão pura prática kantiana ampara a con vicção segundo a qual perguntas normativas podem receber res postas verdadeiras. Para Kant, as apreciações morais e jurídicas que distinguem entre o correto e incorreto, o legítimo e ilegítimo, o justo e injusto não constituem meras expressões lingüísticas de sentimentos familiares como aprovação e reprovação, agrado e desagrado, aversão e simpatia, e assim por diante. Há, segundo Kant, um princípio filosófico moral e jurídico, objetivamente válido e universalmente vinculante, acessível ao conhecimento humano e que estabelece uma linha divisória inalterável entre 0 moralmente permissível e o moralmente condenável, que oferece critérios à luz dos quais a qualidade moral e jurídica das ações humanas, das leis estatais e das organizações do mando político podem ser julgadas.

0 dever de erigir o Estado tem, para Kant, um sólido fundamento no direito de humanidade. Se a cada ser humano assiste o direito de não ser limitado em sua liberdade, a não ser por meio de leis gerais, desse princípio resulta o direito de estabelecer condições sob as quais essas regras genérico-abstratas podem ser formuladas e aplicadas, o que equivale a ter direito às condições que possibilitam, realizam e asseguram a pretensão de viver e agir de acordo com liberdades amparadas por força de lei. "A lei jurídica da razão", escreve W. Kersting, "é um princípio da justiça distributiva especializado na distribuição de liberdade e poder jurídico: só uma rigorosa distribuição igual de liberdade e poder jurídico pode ser uma distribuição justa". ${ }^{1}$

Já o princípio do direito contém a necessidade jurídica de passar da vontade unificada para o complexo da legislação de leis estatais. 0 direito kantiano da humanidade equivale ao direito de usufruir uma liberdade definida e assegurada por leis gerais cujo marco distintivo é a obrigação

\footnotetext{
${ }^{1}$ KERSTING. Wohlgeordnete Freiheit. Immanuel Kants Rechts- und Staatsphilosophie. Frankfurt a/Main: Suhrkamp, 1993, 222. "Ich gebe jedem das Seinige, indem ich jedem durch Gehorsam der staatlichen Gewalt gegenüber die Sicherheit hinsichtlich seines Rechts gebe, (...) und so mit dafür sorge, dass jedem das auf rechtlich-politischem Wege zuteil wird, was ihm als vernünftigem Wesen von Vernunftrechts wegen gegenüber seinesgleichen zusteht."
} 
racional de cumprir o preceito de não lesar ninguém, estabelecendo e mantendo um sistema estatal de segurança jurídica. 0 direito da humanidade implica invariavelmente 0 direito à institucionalização de condições que assegurem sua eficácia normativa. Como a instituição estatal oferece tal segurança, o Estado não é uma grandeza exterior ao direito racional kantiano, mas contém as condições de realização e a eficiência do último. "Sem Estado", escreve Kersting, "o direito racional não iria adquirir realidade no espaço e no tempo" ${ }^{2}$. Segundo Kant, a autonomia política somente é atingida quando o povo por meio de seus representantes tem o domínio sobre si mesmo e a liberdade de todos os cidadãos é limitada unicamente por meio de leis genérico-abstratas que têm a seu favor a presunção da justiça.

Sob este aspecto, o postulado do direito público, derivado explicitamente por Kant do estado natural, não passa de corolário da obrigação necessariamente ligada ao direito de humanidade, a saber: é dever abandonar 0 estado natural (exeundum e statu naturali). "Fazer parte do contrato social", resume Thompson, "constitui o dever absoluto e primário de cada pessoa, de modo que se submeter à obrigação política não é apenas permissivo, mas perfaz uma exigência da razão" ${ }^{3}$.

\section{Posse originária e Estado}

O que é inato a cada homem (meum vel tuum internum) apresenta as mesmas deficiências do meu e teu adquirido, externo a cada homem. No estado natural, o meu-teu externo não se encontra mais indeterminado e mais inseguro do que o meu e teu interno. A lei do direito não precisa menos de socorro da legislação positiva do que os princípios aquisitivos do meu e teu exterior no estado natural. A necessidade do Estado é intrínseca ao direito racional, quer dizer, o postulado do direito público encontra-se já posto na própria lei geral do direito.

Como a posse em comum do solo não tem, em Kant, um significado histórico-empírico grotiano, e considerando que os terráqueos também não se movem sobre uma superfície infinita de solo plano - o que os impede de se espalharem mundo afora sem interagirem uns com os outros - a comunhão da posse originária "deve-se à unidade de todos os lugares sobre a

\footnotetext{
2 Idem. Liberdade e ordenamento. Liberdade \& Liberalismo. Porto Alegre: Edipucrs, 2005, 33.

3 THOMPSON, Kevin. Kant's transcendental deduction of political authority. KantStudien. Berlin, 92, 2001, 62. "Taken together, these ideas led Kant to the startling claim that to place oneself under political obligation is not only a permissible act, but a requirement of reason".
} 
superfície esférica do globo terrestre" ${ }^{4}$, ou seja, consiste numa espécie de comunidade naturalmente imposta, anterior a qualquer ato de aquisição da primeira gleba por quem quer que seja.

De acordo com Kant, a posse inicial comum da terra, advinda do lugar de nascimento ou de circunstâncias quaisquer, é necessariamente uma posse comunitária de indivíduos inter-relacionados. Cada habitante do globo terrestre não apenas tem, segundo o doutrinador alemão, 0 direito inato de poder vir a possuir a terra que 0 vê nascer ou sobre a qual se encontra, mas, em virtude da posse originária em comum, usufrui também do direito de ter qualquer pedaço de terra sobre a superfície do planeta, do tamanho correspondente à força que tem para defender o que ocupa. A communio possessionis originaria kantiana torna possível, em princípio, uma forma de aquisição irrestrita de propriedade. Diferentemente do que ocorre com direitos adquiridos por contrato cujas exigências recíprocas são endereçadas ao respectivo parceiro, o poder de exigir uns dos outros que se abstenham do uso do objeto do arbítrio alheio refere-se a todos os seres humanos. Assim como o neminem laedere (a probição de lesar o próximo) não conhece exceção, a totalidade do gênero humano perfaz, em Kant, 0 titular de obrigações para com a propriedade alheia. A universalização do conflito entre livres-arbítrios leva necessariamente ao impasse, se a vontade de cada homem, observa Kant, "não contém simultaneamente a lei (lex iuridica) de acordo com a qual é possível destinar a cada homem uma posse especial no solo comum" ${ }^{2}$.

Kant deriva a autoridade política da provisoriedade congênita reinante do estado natural de direito. Nesse estado ninguém está obrigado a abster-se da violência em relação à posse alheia, caso "o outro, por sua vez, não ofereça iguais garantias de que se atém igualmente à restrição"6.

A postulação racional em favor do Estado corre, em Kant, paralela com uma teoria não-voluntarista de propriedade. Seu primeiro traço delineia uma interpretação jusfilosófica da primeira apropriação empírica primária de um pedaço de terra, enquanto tomada de posse por parte de um dos titulares da posse originária comum e, num segundo traçado, sedimenta 0

\footnotetext{
${ }^{4}$ KANT, Immanuel. Metaphysische Anfangsgründe der Rechtslehre 262. Hrsg. von B. Ludwig. Hamburg: Meiner, 1986, 71. “[...] wegen der Einheit aller Plätze auf der Erdfläche, als Kugelfläche"

${ }_{5}$ I bidem 267, 77. "Der [J.H. von Natur zustehende Wille], wegen der natürlich unvermeidlichen Entgegensetzung der Willkür des Einen gegen die des Anderen, allen Gebrauch desselben aufheben würde, wenn nicht jener zugleich das Gesetz für diese enthielte, nach welchem einem jeden ein besonderer Besitz auf dem gemeinsamen Boden bestimmt werden kann (lex iuridica)".

${ }^{6}$ I bidem 307, 124-125. "Niemand ist verbunden, sich des Eingriffs in den Besitz des Anderen zu enthalten, wenn dieser ihm nicht gleichmässig auch Sicherheit gibt, er werde ebendieselbe Enthaltsamkeit gegen ihn beobachten".
} 
dever recíproco de unir-se num sistema público armado com determinações jurídicas de caráter material e processual. Na filosofia kantiana da propriedade, o lugar da atuação voluntarista está ocupado por idéias práticas da razão, relativas à comunhão originária de posse do solo e, conseqüentemente, pela vontade a priori unida de todos os envolvidos nessa posse comunitária da terra. Kant escreve:

Mas a lei distributiva do meu e do teu de cada um, relativa ao solo, não pode, de acordo com o axioma da liberdade externa, surgir de outro modo senão que oriundo de uma vontade unificada origináriamente e a priori (que, para tal unificação não pressupõe nenhum ato jurídico), quer dizer, só pode surgir no estado civil (lex iustitiae distributivae), o único estado que determina o que é legítimo, o que é de direito e o que é justo?.

A posição de irrestrita dignidade jurídica, Kant a sustenta com o direito originário de cada ser humano de manter-se, ao lado dos demais, sobre 0 solo onde a natureza o põe ou as contigências da vida o deixam e, assim, Ihe propicia o espaço necessário para fazer uso de sua liberdade. Kant escreve: "Todos os homens encontram-se originariamente na posse comum do solo da terra inteira (communio fundi originaria), munidos pela natureza com vontade própria (e) aptos a fazerem uso dela (lex iusti)" ${ }^{8}$. Essa comunhão originária de posse não-empírica, claramente distinta da suposta comunhão primeva de uma posse historicamente inicial, constitui, segundo Kant, "um conceito prático da razão que contém a priori o princípio de que os homens só podem usar o lugar sobre a terra segundo princípios de direito" ${ }^{9}$.

Como a violência bloqueia a possibilidade de ações livres e põe a vida em risco, o exercício kantiano da liberdade de viver e agir, analisado à luz da ocupação primária da terra, constitui uma das operações fundamentais da razão ${ }^{10}$. Devido à indeterminação relativa à quantidade e qualidade do

\footnotetext{
7 I bidem 267, 77. "Aber das austeilende Gesetz des Mein und Dein eines jeden am Boden kann, nach dem Axiom der äusseren Freiheit, nicht anders als aus einem ursprünglich und a priori vereinigten Willen (der zu dieser Vereinigung keinen rechtlichen Akt voraussetzt), mithin nur im bürgerlichen Zustand hervorgehen (lex iustitiae distributivae), der allein was recht, was rechtlich, und was rechtens ist, bestimmt" .

8 Ibidem. "Alle Menschen sind urprünglich in einem Gesamt-Besitz des Bodens der ganzen Erde (communio fundi originaria), mit dem ihnen von Natur zustehenden Willen (eines jeden) densel ben zu gebrauchen (lex iusti)".

${ }^{9}$ I bidem 262, 72. "Der Besitz aller Menschen auf Erden, der vor allem rechtlichen Akt derselben vorhergeht (von der Natur selbst konstituiert ist), ist ein ursprünglicher Gesamtbesitz (communio possessionis originaria), dessen Begriff nicht empirisch und von Zeitbedingungen abhängig ist, wie etwa der gedichtete, aber nie erweisliche eines uranfänglichen Gesamtbesitzes (communio primaeva), sondern ein praktischer Vernunftbegriff, der a priori das Prinzip enthält, nach welchem allein die Menschen den Platz auf Erden nach Rechtsgesetzen gebrauchen können".

10 THOMPSON. Kant's transcendental deduction of political authority. Kant-Studien. Berlin, 92, 2001, 76. "It accounts for the legitimate usage of the concept of state authority by tracing its conceptual origin back, through an analysis of property acquisition, to one of the fundamental operations of human reason".
} 
objeto exterior adquirido, cabe no estado natural à violência dirimir conflitos de propriedade. Sem conversão da idéia de arbítrio unido a priori em autoridade de um poder institucionalmente constituído, ou seja, sem a constituição do status civilis, a concepção kantiana de propriedade não tem como coibir a violência ou limitar os efeitos nefastos da mesma entre os seres humanos. Por mais legítima que seja, a prima occupatio não passa de um direito provisório à espera de um estado jurídico peremptório.

A relação estabelecida por Kant entre propriedade e Estado é visceral. Caso não haja aquisição primária, o Estado fica inviável e sem Estado a propriedade permanece incerta. De acordo com Th. Hobbes, os homens abandonam o estado natural para salvar sua vida e liberdade e não, primariamente, para assegurar suas posses. 0 caráter político da teoria estatal hobbesiana é concebido e fundamentado à revelia da doutrina da propriedade. Para o teórico político inglês, a propriedade constitui um instituto jurídico-positivo criado, mantido e instrumentalizado pelo poder político como estratégia pacificadora do state of nature.

Em J. Locke, tem-se a situação diametralmente oposta. A propriedade não constitui recurso político de um Estado com incumbência soberana frente à posse; o Estado lockiano é tout court um instrumento da propriedade, concebido exterior a ela e posto a serviço dela como ser jurídico interessado na melhor solução dos problemas que envolvem títulos de propriedade. Em lugar de um Estado soberano frente à propriedade, de um lado, e de uma propriedade independente do Estado, de outro, ocorre em Kant o cruzamento teórico entre a validez da propriedade e a validade do Estado cujo ponto de intersecção instala entre as duas grandezas jurídicas uma interdependência mútua e perene. Para o jurista racional alemão, o Estado mantém suas raízes na propriedade e essa, por sua vez, tende ao Estado não apenas por razões de segurança, mas também com vistas à completude do instituto jurídico enquanto tal.

No Estado hobbesiano há justiça distributiva quando títulos de propriedade, concedidos pelo ordenamento jurídico, são amparados por força de lei. Tal conceito de justiça não contém critérios conteudísticos que distingam partilhas justas e injustas de propriedade. Por justiça Hobbes entende a articulação entre legislação, juridição e execução que substitui a impotência do direito jusnaturalista por um direito positivo prenhe de autoridade, justificado pelo Estado e revestido de poder absoluto, destinado à manutenção da paz entre os homens. Kant assume o preceito hobbesiano da justiça distributiva, ao prescrever obediência às leis do Estado e respeito para com o direito alheio positivado em lei. 0 caminho que leva à justiça é o caminho que sai do estado natural e entra no Estado de direito. "O Estado que assegura o direito", doutrina Kersting, "é a justiça"11.

${ }^{11}$ KERSTING. Vernunftrecht, Gerechtigkeit und Rechtsverbindlichkeit bei Kant. Porto Alegre, 2003, 10 (mimeo). "Der rechtssichernde Staat ist die Gerechtigkeit". 
O sistema da justiça distributiva é, para Kant, o sistema do senhorio estatal que gera, por meio da legislação, dos tribunais e do poder executivo, um estado generalizado de segurança pública. Visto sob visor hobbesiano, a teoria kantiana de propriedade eleva a vontade geral unificada, validada pelo Estado, ao patamar de um fundamento teórico-jurídico consistente de propriedade. 0 salto dado por Kant entre a modalidade de relações provisórias, relativas a posses e títulos no estado natural, e a modalidade de relações peremptórias dos mesmos no estado civil "traz consigo", segundo Kersting, "não apenas um acréscimo de segurança, mas abarca também um acúmulo em qualidade da validação teórica"12.

A institucionalização kantiana do direito racional não responde, na esteira de Hobbes, a perguntas relativas aos critérios que regem a justiça distributiva e é irreconciliável com a concepção lockiana da propriedade do trabalho e o modelo transparente de justiça distributiva que caracteriza essa concepção. Locke considera a justiça de uma distribuição de posses, por um lado, como função da justiça da aquisição originária de bens e, por outro, como função da justiça relativa à transferência de posses. 0 princípio lockiano da aquisição justa é satisfeito quando o direito da propriedade, constituído pelo trabalho, não frustra a autopreservação dos seres humanos, o que é invariavelmente o caso quando são observados os limites do direito à própria subsistência e o direito à sobrevivência do próximo. 0 filósofo inglês não tem nenhuma razão para incumbir o Estado com a institucionalização da justiça. Tarefa do Estado é, segundo Locke, estabilizar e acalmar a ordem natural da propriedade privada por meio de uma legislação precisa e de instâncias ágeis movidas pelo zelo de proferir decisões claras e acessíveis a todos.

0 ponto de arrancada da teoria kantiana da propriedade é idêntico à teoria proposta por Locke. Os dois descartam a fundamentação grotiana da propriedade por intermédio de um acordo convencional explícito ou tácito ${ }^{13}$, isto é, um e outro rejeitam uma origem contratualista da propriedade e operam com a possibilidade de uma aquisição primária unilateral. Assim procedendo, ambos precisam esclarecer como um indivíduo adquire, originária e arbitrariamente, 0 direito sobre determinada gleba num planeta habitado conjuntamente por todos os homens e pode legitimamente sustar a qualquer um, que não esteja autorizado, o acesso a essa porção de solo,

\footnotetext{
12 Idem. Der Staat der Vernunft. Porto Alegre, 2003, 7 (mimeo). “Der Modalitätssprung des allgemeinen Rechts- und Besitzverhältnissen im Naturzustand zu peremptorischen Rechts- und Besitzverhältnissen im Zivilzustand beinhaltet nicht nur einen Sicherungszuwachs, er umfasst auch eine geltungstheoretische Qualitätssteigerung".

${ }_{13}$ À pergunta "quomodo res in proprietatem iverint", Grotius responde: "pacto quodam aut expresso, ut per divisionem, aut tacito, ut per occupationem: simul atque enim communio displicuit, nec instituta est divisio, censeri debet inter omnes convenisse, ut, quod quisque occupasset, id proprium haberet" (De jure belli ac pacis II, 2,2,5).
} 
quando está excluído, até aquele momento, que o objeto não é sem dono (res nullius), mas é, desde os dias da criação, de todos os terráqueos solidariamente. Locke pondera:

Deus, que deu o mundo aos homens em comum, deu-Ihes também a razão, a fim de que dela fizessem uso para maior benefício e conveniência da vida. A Terra, e tudo quanto nela há, é dada aos homens para o sustento e 0 conforto de sua existência. E embora todos os frutos que ela naturalmente produz e os animais que alimenta pertençam à humanidade em comum, produzidos que são pela mão espontânea da natureza, e ninguém tenha originalmente um domínio particular sobre eles à exclusão de todo resto da humanidade, por estarem todos em seu estado natural, é, contudo, necessário, por terem sido essas coisas dadas para uso dos homens, haver um meio de apropriar parte delas de um modo ou de outro para que possam ser de alguma utilidade ou benefício para qualquer homem em particular ${ }^{14}$.

Conforme exposta, a apropriação privada é o único caminho pelo qual os bens desse mundo podem ser destinados aos fins que lhes são inerentes. Uma disposição contratual não vem ao caso para o doutrinador liberal, pois "fosse tal consentimento necessário", argumenta ele, "o homem teria morrido de fome, não obstante a abundância com que Deus o proveu"15.

\section{Propriedade e trabalho}

As teorias da apropriação originária seguem, em Locke como em Kant, o mesmo esquema racional, ou seja, quando um homem assume determinada conduta em relação a certo objeto ele fica o dono do mesmo e adquire em relação aos demais seres humanos o direito de excluí-los do uso do objeto e, com base no poder de coação, ligado analiticamente ao direito adquirido, pode constrangê-los pela força a se ater ao que está disposto. 0 modo privado da apropriação é prático e, além disso, necessário para a consecução dos fins da criação.

\footnotetext{
${ }^{14}$ LOCKE, J ohn. Two treatises of government II, 26. Ed. By P. Laslett. Cambridge: University Press, 1994, 286-287. "God, who hath given the World to Men in common, hath also given them reason to make use of it to the best advantage of Life, and convenience. The Earth, and all that is therein, is given to Men for the Support and Comfort of their being. And though all the Fruits it naturally produces, and Beasts it feeds, belong to Mankind in common, as they are produced by the spontaneous hand of Nature; and no body has originally a private Dominion, exclusive of the rest of Mankind, in any of them, as they are thus in their natural state: yet being given for the use of Men, there must of necessity be a means to appropriate them some way or other before they can be of any use, or all beneficial to any particular Man".

15 I bidem II, 28, 288. "If such a consent as that was necessary, Man had starved, notwithstanding the Plenty God had given him".
} 
Ao mostrar como a apropriação jurídica pode ocorrer, tendo em vista os pressupostos do domínio inicial comum, Locke recorre à doutrina tradicional do suum jusnaturalista, segundo a qual o termo propriedade referese a tudo o que é próprio a alguém, como a vida, o corpo e seus membros, a liberdade, a honra e assim por diante, e articula sua concepção de propriedade com base no trabalho. De acordo com ela, vale para todas as pessoas físicas e todos os objetos naturais - dos frutos da terra ao solo em si - que alguém, ao investir trabalho num bem natural de modo a alterar sua naturalidade, 0 agente adquire um direito de propriedade nesse objeto e fica devidamente autorizado a excluir todos os seus semelhantes do uso desse objeto.

"Embora a Terra e todas as criaturas inferiores sejam comuns a todos os homens", raciocina Locke, "cada homem tem uma propriedade em sua própria pessoa. A esta ninguém tem direito algum além dele mesmo". 0 filósofo inglês não predica aos gestos do trabalho empírico, enquanto tais, uma função constitutiva para a aquisição da propriedade. As conseqüências normativas da aquisição tornam-se visíveis tão-somente quando as ações do agente são por sua vez integradas num contexto normativo, chamado por Locke de propriedade em sua própria pessoa. "O trabalho de seu corpo e a obra de suas mãos", escreve Locke, "pode-se dizer, são propriamente dele". Pelo trabalho a pessoa se mescla com a natureza, acrescenta-Ihe algo de próprio e altera, assim, parte do domínio comum, de modo que a posse do objeto não mais é abarcada pelo direito alheio. "Qualquer coisa que ele então retire do estado com que a natureza a proveu e deixou", explica Locke, "mistura-a ele com o seu trabalho e junta-Ihe algo que é seu, transformando-a em sua propriedade". Pelo trabalho investido no objeto a qualidade jurídica da pessoa passa para a esfera do objeto, vale dizer, sendo a propriedade retirada do estado comum no qual se encontrava por disposição natural, o homem "agrega com esse trabalho", diz Locke, "algo que a exclui do direito comum dos demais homens". O objeto é, assim, integrado na esfera inessiva do homem, própria ao agente, a ponto de tornar-se uma parte dele mesmo. "Por ser esse trabalho propriedade inquestionável do trabalhador", conclui Locke, "homem nenhum além dele pode ter direito àquilo que a esse trabalho foi agregado [...]"16.

\footnotetext{
16 Ibidem II, 27, 287-288. "Though the Earth, and all inferior Creatures be common to all Men, yet every Man has a Property in his own Person. This no Body has any Right to but himself. The Labour of his Body, and the Work of his Hands, we may say, are properly his. Whatsoever then he removes out of the State that Nature hath provided, and left it in, he hath mixed his Labour with, and joyned to it something that is his own, and thereby makes it his Property. It being by him removed from the common state Nature placed it in, it hath by this Labour something annexed to it, that excludes the common right of other Men. For this Labour being the unquestionable Property of the Labourer, no Man but he can have a right to what that is once joyned to, at least where there is enough, and as good left in common for others".
} 
Como modelo de subjetivação, a idéia do repasse da qualidade jurídica pessoal a objetos por meio do trabalho constitui o núcleo mais resistente da teoria lockiana liberal e ou comunitarista da propriedade ${ }^{17}$. Segundo Kersting, tal teoria combina três teses: a) o homem é proprietário de sua personalidade e suas ações, b) pela operação do trabalho num objeto a personalidade mistura-se com o objeto, c) com isso, a propriedade do agente que trabalha alarga-se graças à posse jurídica da mescla com sua personalidade ${ }^{18}$.

Locke não responde à pergunta que quer saber algo sobre a possibilidade de um meu externo. Sua teoria da propriedade consiste na tentativa de reconstruir o meu externo como parte constitutiva do meu interno, procurando erigir uma ponte entre meu interno e propriedade, alheio a toda mediação de caráter generalizante, seja de teor jusnaturalista, seja do tipo ideal de uma comunidade solidária constituída de titulares de posses, responsável, em Kant, pela justificação da tomada empírica do solo como primeira aquisição juridicamente significativa de um pedaço de terra. Ao eliminar da teoria da propriedade qualquer resquício de consenso ou acordo, Locke esvazia o conceito de posse contido no aforismo "which God gave to Mankind in common" de suas aparentes conotações jurídicas ${ }^{19}$. Caso o globo terrestre esteja na posse de todos os homens desde os dias da criação, como o pensador inglês não cansa de repetir, não é compreensível que a apropriação via trabalho dê cobertura e consistência ao direito do recém proprietário de excluir todos os demais titulados à posse comum do solo terrestre $\mathrm{e}^{20}$.

À luz da teoria lockiana da propriedade pelo trabalho os cotitulares da posse comum perdem, como co-habitantes do planeta Terra, a estatura de parceiros jurídicos. Locke os trata como figuras indigentes cujo direito à subsistência não deve ser vilipendiado pelo direito da propriedade. Para 0 doutrinador inglês, Deus deu de tudo em abundância ao gênero humano para que qualquer pessoa possa fazer uso de qualquer coisa, adquiri-la por meio do trabalho e dela usufruir exclusivamente a seu bel-prazer. "O que

${ }^{17}$ Cf. KRAMER, Matthew H. Collectivism contra collectivism. J ohn Locke and the origins of private property. Philosophical exploration of individualism, community, and equality. Cambridge: University Press, 1997, 23-33.

${ }^{18}$ KERSTING. Vernunftrecht und Eigentumsbegründung. Porto Alegre, 2003, 12 (mimeo). “(I) Der Mensch ist Eigentümer seiner Persönlichkeit und seiner Handlungen. (II) Durch die Bearbeitung eines Gegenstandes vermischt sich die Persönlichkeit mit dem Gegenstand. (III) Damit wird das Eigentum des arbeitenden Menschen um den rechtlichen Besitz des mit seiner Persönlichkeit Vermischten erweitert".

${ }^{19}$ LOCKE. Two treatises of government II, 25. loc. cit. 286.

${ }^{20}$ KERSTING. Wohlgeordnete Freiheit. I mmanuel Kants Rechts- und Staatsphilosophie. Frankfurt am Main: Suhrkamp, 1993, 286. "Ist die Erde im Besitz aller, dann ist es unverständlich, dass durch Aneignung und Bearbeitung ein Rechts auf Ausschluss aller Mitbesitzer entstehen kann. 
quer que esteja além disso", admoesta o pai do liberalismo político, "excede sua parte e pertence aos outros"21.

A teoria de aquisição da propriedade é correta e, simultaneamente, supérflua. 0 criador é dono de suas criações na medida em que as últimas são objetivações de sua vontade. A substância material do solo, porém, não se dilui em subjetividade graças ao trabalho, a terra trabalhada pelas mãos do homem não é um produto direto do livre-arbítrio do trabalhador, mas constitui antes o seu limite e o remete à alteridade do que é subjetivo, livre e inventivo.

Kant combate tardiamente, na Doutrina do direito, a concepção lockiana (e rousseauniana) da origem da propriedade, ao responder negativamente à pergunta se, "para adquirir um pedaço de terra é necessário ter executado trabalhos em sua superfície (construções, cultivo, saneamento, e assim por diante)"; Kant advoga que "[...] o cultivo, por ocasião da primeira aquisição não passa de um signo exterior da tomada de posse, signo que pode ser substituído por outros muito menos onerosos" 22 .

Enquanto na teoria lockiana a causa fundante, o suporte explicativo e a sustentação de validade da propriedade convergem, o doutrinador alemão distingue claramente a base empírica do plano normativo. Para Kant, o trabalho não sinaliza uma misteriosa expansão dos domínios da vontade e da esfera da personalidade no mundo das coisas, capaz de submeter membros corpóreos, utensílios e ferramentas ao universo da vontade, mas perfaz uma ação empírica que necessita de ser reconstruída significativamente para 0 universo da intersubjetividade. Uma coisa é submeter a natureza aos propósitos do homem e imprimir nos objetos o cunho do espírito humano, outra bem diferente é fundamentar o uso exclusivo de uma coisa, legitimando a exclusão dos demais. No segundo caso, lembra Kersting, "temos uma limitação do livre-arbítrio alheio que, por não ser imediatamente derivável do direito da humanidade, necessita de uma forma de assentimento à revelia da dificuldade teórica de reconstruir adequadamente tal anuência" 23.

\footnotetext{
${ }^{21}$ LOCKE. Two treatises of government II, 25. Ioc. cit. 286. "Whatever is beyond this, is more than his share, and belongs to others".

22 KANT. Metaphysische Anfangsgründe der Rechtslehre, 265, loc. cit. 204-205. "Ist die Bearbeitung des Bodens (Bebauung, Beackerung, Entwässerung u. dgl.) zur Erwerbung dessel ben notwendig? Nein (...). Die Bearbeitung ist, wenn es auf die Frage von der ersten Erwerbung ankommt, nichts weiter als ein äusseres Zeichen der Besitznehmung, welches man durch viele andere, die weniger Mühe kosten, ersetzen kann".

${ }^{23}$ KERSTING. Vernunftrecht und Eigentumsbegründung, loc. cit. 13 (mimeo). "[...] denn letzteres ist eine Einschränkung fremder Willkür und bedarf, da nicht unmittelbar aus dem Menschheitsrecht ableitbar, deren wie auch immer im einzelnen theoretisch zu rekonstruierender Zustimmung".
} 
0 fato de o filósofo erigir o postulado do direito público nas imediações das aporias do direito privado pode levar à tese de que o Estado kantiano ostenta uma marca exclusivamente privada e que o doutrinador alemão subestima a capacidade do direito racional de sustentar princípios: os conflitos de posse são as únicas razões que os homens têm para abandonarem o estado natural. Por um lado, o postulado do direito público pode ser adquirido da pura lei do direito no estado natural, uma vez que as leis necessárias para assegurar a liberdade inata do homem só podem proceder da autolegislação daqueles que se unem para fazerem as leis. Por outro lado, sem indicação das carências legais apriorísticas, relativas ao uso adequado das coisas no estado natural de convivência, o imperativo jurídico de abandonar o status naturae não passaria de um gesto humanista ou seria mera recomendação.

0 ato originário pelo qual alguém toma posse física (apprehensio physica) de uma porção específica de solo concede, segundo Kant, somente um título empírico de aquisição do objeto em questão. Para que o título da posse fenomenal seja legitimado, é necessário que uma "apreensão intelectual (abstração feita de todas as condições empíricas no espaço e no tempo) corresponda ao ato originário de posse" ${ }^{24}$, amparando assim o ocupante em sua reivindição de que sua posse, por não ter limites de espaço e tempo, é de tal ordem que qualquer outro homem fica excluído do uso da gleba adquirida. Tal obrigação coibe recíproca e universalmente. Ocorre, porém, que a exigência não pode ser satisfeita por um ato unilateral, razão por que 0 direito estabelecido pela ocupação originária de um pedaço de terra permanece provisório. Como, pois, é possível que um ato solitário consiga impor uma obrigação recíproca a todos os membros da comunidade original, vale dizer, como pode o direito do indivíduo advindo da tomada de posse originária tornar-se conclusivo, seguro e peremptório?

De acordo com Kant, uma obrigação universalmente abrangente requer que 0 ato originário da aquisição não seja apenas expressão de uma vontade individual, mas configure "uma vontade omnilateral, não casual senão a priori, impreterivelmente comum e unida e, por isso mesmo, legisladora" 25 . Kant concede que tanto a indeterminabilidade em relação à quantidade e qualidade de um objeto exterior suscetível de aquisição, "torna o problema da resolução da aquisição originária o mais difícil de todos"26,

\footnotetext{
${ }^{24}$ KANT. Metaphysische Anfangsgründe der Rechtslehre 264, loc. cit. 203-204. “[...] weil dem Besitz nach Vernunftbegriffen des Rechts nur ein Besitz in der Erscheinung unterlegt werden kann, der einer intellektuellen Besitznehmung (mit Weglassung aller empirischen Bedingungen in Raum und Zeit) korrespondieren muss [...]".24

${ }_{25}$ I bidem 263, 72. "[...] sondern dazu wird ein allseitiger, nicht zufällig, sondern a priori, mithin notwendig vereinigter und darum allein gesetzgebender Wille erfordert".

${ }_{26}$ Ibidem 266, 206. "Die Unbestimmtheit in Ansehung der Quantität sowohl als der Qualität des äusseren erwerblichen Objekts, macht diese Aufgabe (der einzigen ursprünglichen Erwerbung) unter allen zur schwersten sie aufzulösen".
} 
mas insiste: "de qualquer modo, alguma aquisição exterior tem que haver, pois toda a aquisição não poder ser derivada"27. 0 doutrinador do direito racional admite, em conseqüência, que a vontade de quem ocupa primeiramente um pedaço de terra deve ser entendida como articulada num estado unificado por uma vontade omnilateral, portanto, não como ato ocasional, mas como expressão de um "contrato originário" cuja virtualidade "nunca seria mais que provisória, se esse contrato não fosse extensivo a todo gênero humano" 28 .

0 que une a vontade de alguém com os semelhantes é o fato de que em qualquer parte do planeta, ao ser adquirido algo por alguém, é feito um exercício de escolha como afirmação e reconhecimento do conceito inteligível de posse. $\mathrm{Na}$ ocupação originária é sustentado que o objeto em questão é apropriado de uma maneira que transcende os limites do emprego da força bruta e ultrapassa os limites empíricos de espaço e tempo. Ao proceder desse modo, 0 agente jurídico encontra-se, simultaneamente, conectado com o Princípio geral do direito e está autorizado a usar a força. Segundo Kant, cada tomada de posse ratifica a validade mútua e universal da proposição-mor do direito racional. Assim, pode dizer-se que a estrutura do ato originário de aquisição é ao mesmo tempo unilateral e omnilateral29. Kant remete os gestos empíricos da prima occupatio de volta a sua origem, a saber: ao conceito inteligível de posse. A apropriação do objeto, providenciada pela aquisição originária somente é possível sob a regência da idéia do contrato originário, pelo qual fica expresso a vontade unificada e comprometida com a obrigação inerente ao direito de possuir e adquirir propriedade. Nesse sentido, conclui Thompson, "a sustentação de Kant do exercício da liberdade prática, no ato da aquisição originária, constitui uma dedução transcendental da autoridade política" ${ }^{30}$.

\section{Conclusão}

Para Kant, não mais a natureza insociável ou até má do ser humano, mas o conceito do livre-arbítrio e o fato inevitável de viver lado a lado assumem o ônus da prova do estado de natureza, como estado não-jurídico

\footnotetext{
27 I bidem. "Irgend eine ursprüngliche Erwerbung des Äusseren aber muss es indessen doch geben; denn abgeleitet kann nicht alle sein".

${ }^{28}$ I bidem. "Aber, wenn sie auch durch den ursprünglichen Vertrag aufgelöst wird, so wird, wenn dieser sich nicht aufs ganze menschliche Geschlecht erstreckt, die Erwerbung doch immer nur provisorisch bleiben".

${ }^{29}$ THOMPSON, loc. cit. 75. "In this sense, one can say that the structure of the original act of acquisition is at once unilateral and omnilateral".

${ }^{30}$ I bidem, 76. "In this way Kant's account of the exercise of practical freedom in the act of original acquisition constitutes a transcendental deduction of political authority".
} 
cuja função consiste em dar o contraste à imanente normatividade do status iuridicus. "O estado de natureza é, portanto, essencialmente para Kant 'o estado do direito privado'", escreve Kersting, "uma construção conceitual, um experimento mental, no qual é concebido um estado onde os homens interagem de acordo com determinações provindas do direito privado" 31 e cuja carga explosiva consiste na multiplicidade de opiniões jurídicas e interpretações do direito privado, invariavelmente equivalentes entre si.

Diferentemente do que Hume supõe, the original contract não constitui fato histórico e tampouco registra o começo de uma existência estatal. 0 designativo "contrato originário", usado por Kant, assinala o estatuto eminentemente racional do contrato. Originário não equivale a primordial ou a primitivo. Primordial e originário estão um para o outro como empírico e racional. 0 que chega dos primórdios está marcado pelo tempo, fixa o início imemorial de uma seqüência histórica, ao passo que o originário indica a base e contempla razões. 0 que é originário não narra uma história, mas traz um argumento. Desde Kant, boa parte das objeções contra o contratualismo acerta no vazio, uma vez que o contrato social não rememora 0 atemporal, mas sinaliza o fundamento da origem ${ }^{32}$.

0 fundamento contratualista kantiano não se refere ao contrato enquanto causa geradora de vínculos interpessoais. Tais efeitos só podem resultar de pactos efetivamente celebrados. O contratualista Kant toma por objeto contratual as razões que assistem a cada homem quando se une aos demais na instauração de uma ordem societária comum. As razões aqui em jogo são idênticas àquelas que levam alguém a preferir determinada ordem social em detrimento de outros ordenamentos; a qualidade das razões que falam a favor de determinada modelo social, enquanto objeto de possível união, é totalmente alheia à questão de saber se a hipotética unificação ocorre ou não historicamente. 0 contrato constitui, para Kant, um critério epistêmico-moral, vale dizer, não diz respeito a efeitos de vinculação individual, mas responde a princípios universais passíveis de um reconhecimento recíproco e público a serviço da paz.

Kant é responsável pelo desaparecimento do estado hobbesiano isento de uma matriz de propriedade, bem como pelo descrédito da propriedade

\footnotetext{
${ }^{31}$ KERSTING. Wohlgeordnete Freiheit. Immanuel Kants Rechts- und Staatsphilosophie, loc. cit. 332. "Der Naturzustand ist bei Kant also wesentlich der 'Zustand ... des Privatrechts', eine begriffliche Konstruktion, ein Gedankenexperiment, in dem ein Zustand vorgestellt wird, in dem die Menschen einander nach Massgabe der privatrechtlichen Bestimmungen begegnen" [...]".

32 HÖFFE, Otfried. Ist Kants Rechtsphilosophie noch aktuell? In: HÖFFE (Hrsg.). Metaphysische Anfangsgründe der Rechtslehre. Berlin: Akademie Verlag, 1999, 282. “Der Gesellschaftsvertrag besteht nicht in einem uranfänglichen, sodern einem 'ursprünglichen Kontrakt'.
} 
lockiana fincada fora do estado político. A paz kantiana, como sumo bem político, não tem à disposição o movimento aristotélico que se esgota em usufruir seus respectivos fins, mas apenas conta com movimentos que vão, ininterruptamente, do alcance de um fim ao alcance de outro fim. Estado e propriedade são os componentes fundamentais da paz entre os homens. A força que mantém os indivíduos em vida é inexplicável como telos, fim, objetivo. Não há fruição última e definitiva do bem.

\section{Referências}

BRANDT, Reinhard. Eigentumstheorien von Grotius bis Kant. Stuttgart-Bad Cannstatt, 1974.

CICERO, Tulius. De officiis III, 6. Oeuvres complètes. Trad. do latim por M. Nisard. Paris: Dislot, 1859, p. 85. (edição bilíngüe).

CHWASZCZA, Christine. Praktische Vernunft als vernünftige Praxis. Weilerswist: Velbrück Wissenschaft, 2003.

FRIEDRICH, Rainer. Eigentum und Staatsbegründung in Kants Metaphysik der Sitten. Berlin/New York: de Gruyter, 2004.

FULDA, Hans-F. Kants Postulat des öffentlichen Rechts. Jahrbuch für Recht und Ethik, Berlin.

GOUDELI, Kyriaki. Kant's Reflective Judgement: The Normalisation of Political Judgement. Kant-Studien. Jhrg. 94, Heft. 1, Berlim, 2003.

HABERMAS, Jürgen. Kants Idee des ewigen Friedens - aus dem historischen Abstand von 200 Jahren. In: Die Einbeziehung des Anderen. Studien zur politischen Theorie. 2. Aufl. Frankfurt a/Main: Suhrkamp, 1996.

HECK, José N. Thomas Hobbes. passado e futuro. 1. reimpressão. Goiânia: Editoras UFG/UCG, 2004.

. Contratualismo e sumo bem político. Um estudo prelimianr sobre a pax kantiana. Porto Alegre. Veritas, v. 49, n. 1, 2004.

HEIDBRINK, Ludger. Kritik der Verantwortung. Zu den Grenzen verantwortlichen Handelns in komplexen Kontexten. Weilerswist: Velbrück Wissenschaft, 2003.

HERB, Karlfriedrich. Bürgerliche Freiheit (Kant). Freiburg/München: Verlag K. Alber, 1999.

HERB \& LUDWIG. Naturzustand, Eigentum und Staat. Immanuel Kants Relativierung des 'Ideal des Hobbes'". Kant-Studien, 83, Berlin.

HÖFFE, Otfried. O imperativo categórico do direito: uma interpretação da "Introdução à Doutrina do Direito". Studia Kantiana, Rio de Janeiro, v. 1, n. 1, p. 203234, 1998.

Gerechtigkeit. Eine philosophische Einführung. München: Verlag Beck, 
. Visão república mundial. Democracia na era da globalização. In: OLIVElRA \& SOUZA (Org.). Justiça e política. Homenagem a Otfried Höffe. Porto Alegre: Edipucrs, 2003.

LOCKE, John. Two treatises of government. Ed. By P. Laslett. Cambridge: University Press, 1994.

KANT, Immanuel. Metaphysische Anfangsgründe der Rechtslehre. Hrsg. von B. Ludwig. Hamburg: Meiner, 1986.

. Kritik der praktischen Vernunft. Hrsg. von K. Vorländer. 9. Aufl. Hamburg: F. Meiner, 1967.

.̈̈ber den Gemeinspruch (Vom Verhältnis der Theorie zur Praxis im Staatsrecht (gegen Hobbes); Vom Verhältnis der Theorie zur Praxis im Völkerrecht. In allgemein-philanthropischer, d.i. kosmopolitischer Absicht betrachtet (gegen Moses Mendelssohn). Hrsg. von H.-F. Klemme. Hamburg: F. Meiner, 1992.

. Zum ewigen Frieden. Hrsg. von H.-F. Klemme. Hamburg: F. Meiner, 1992.

- Idee zur einer allgemeinen Geschichte in weltbürgerlicher Absicht. In: Kleiner Schriften zur Geschichtsphilosophie, Ethik und Politik. Hrsg. von K. Vorländer. Hamburg: F. Meiner, 1973.

KAULBACH, F. Studien zur späten Rechtsphilosophie Kants und ihrer transzendentalen Methode. Würzburg: Königshausen \& Neumann, 1982.

. Das tranzendental-juridische Grundverhältnis im Vernunftbegriff Kants und der Bezug zwischen Rechts und Gesellschaft. In: KAULBACH \& KRAWIETZ (Hrsg.). Rechts und Gesellschaft. Festschrift für H. Schelsky. Berlin: de Gruyter, 1988.

. Rechtsgehorsam und Gerechtigkeit bei Kant. In: KORFF, F.-W. (Hrsg.) Redliches Denken. Festschrift für G.-G. Grau. Stuttgart-Bad Cannstatt: Frommann Holzboog, 1982.

KERSTING, Wolfgang. Politics, freedom, and order: Kant's political philosophy. In: GUYER, P. A companion to Kant. Cambridge, Mass. Cambridge University Press, 1992.

. Pax Kantiana. Towards a political philosophy of International Relations. Ärchiv für Rechts- und Sozialphilosophie LXXX, 1994.

. Globale Rechtsordnung oder weltweite Verteilungsgerechtigkeit? Über den systematischen Grundriss einer politischen Philosophie der internationalen Beziehungen. In: GERHARDT \& OTTMANN \& THOMPSON (Hrsg.). Politisches Denken. Jahrbuch 1995/6. Stuttgart: Metzler, 1995.

. Die Gerechtigkeit zieht die Grenzen, und das gute setzt das Ziel. In: HOFFE, O. (Hrsg.). John Rawls: Theorie der Gerechtigkeit. Berlin: Akademie Verlag, (Reihe: Klassiker Auslagen), 1998.

. Die Vertragsidee des Contract social und die Tradition des neuzeitlichen. Kontraktualismus. In: BRANDT \& HERB (Hrsg.). Jean-JacquesRousseau: Vom Gesellschaftsvertrag oder Prinzipien des Staatsrechts. Berlin: Akademie Verlag, (Reihe: Klassiker Auslegen), 2000.

. Wohlgeordnete Freiheit. Immanuel Kants Rechts- und Staatsphilosophie. Frankfurt a/ M ain: Suhrkamp, 1993. 
. Über die Grenzen der Gerechtigkeit und der Moral. Weilerswist: Velbrück W issenschaft, 2002.

. Jean-Jacques Rousseaus "Gesellschaftsvertrag". Darmstadt: W issenschaftliche Buchgesellschaft, 2002.

. Vernunftrecht, Gerechtigkeit und Rechtsverbindlichkeit bei Kant. Porto Alegre, 2003 (mimeo),

- Kant über Recht. Paderborn: Mentis Verlag, 2004.

. Liberdade \& liberalismo.Trad. do alemão por Luís M. Sander. Porto Alegre: Edipucrs, 2005 (Coleção Filosofia).

. Gerechtigkeit und Lebenskunst. Philosophische Nebensachen. Paderborn: Mentis Verlag, 2005.

KÖNIG, Peter. Autonomie und Autokratie. Über Kants Metaphysik der Sitten. Berlin/ New York : de Gruyter, 1994.

KRAMER, Matthew H. Collectivism contra collectivism. John Locke and the origins of private property. Philosophical exploration of individualism, community, and equality. Cambridge: University Press, 1997.

LOPARIC, Zelyko. O problema fundamental da semântica jurídica kantiana. WRIGLEY \& SMITH (Org.). O filósofo e sua história. Uma homenagem a Oswaldo Porchat. Campinas: Unicamp, Centro de Lógica, Epistemologia e História da Ciência, 2003 (Col. CLE; v. 36).

LUDWIG, Bernd. Kants Rechtslehre. Hamburg: Meiner, 1988 (Kant-Forschungen). THOMPSON, Kervin. Kant's transcendental deduction of political authority. KantStudien. Berlin, 92, 2001.

WOOD, Allen W. Kant's doctrine of right: Introduction. In: Immanuel Kant. Metaphysische Anfangsgründe der Rechtslehre. Hrsg. von 0. Höffe. Berlin: Akademie Verlag, 1999 (Klassiker Auslegen).

Endereço do autor:

Av. T-4 C/ T-65 - Setor Bueno

Ed. B. Landeiro, 1077/A 903

74.230-120 Goiânia - GO

e-mail: heck@ih.com.br 